\title{
A utilidade da citologia por punção com agulha fina aliada a imunofenotipagem no diagnóstico dos linfomas não-Hodgkin
}

\section{Diagnosis of non-Hodgkin's lymphoma combining immunophenotyping and fine needle aspiration}

\section{Flávia P. S. Costa}

Fernanda G. Pereira ${ }^{I}$

José Vassalo ${ }^{2}$

Leandro L. L. Freitas ${ }^{2}$

Irene Lorand-Metze $e^{l}$

\begin{abstract}
A classificação para linfomas não-Hodgkin (LNH) proposta pela Organização Mundial da Saúde (OMS) enfatiza a importância do imunofenótipo para o diagnóstico. O objetivo deste estudo foi avaliar a utilidade da citologia combinada a citometria de fluxo para o diagnóstico de LNH, utilizando um painel de anticorpos monoclonais e estudo do ciclo celular. $O$ material foi obtido através de aspiração de linfonodos por agulha fina de 78 pacientes. O painel de anticorpos monoclonais para análise em citometria de fluxo foi o seguinte: $C D 19 / C D 10, C D 20 / C D 5, C D 23, C D 38 / C D 7, C D 3 / C D 4, C D 3 /$ CD8, kappa/lambda. O diagnóstico final foi confirmado pela histologia convencional, considerada gold standard. Em 85\% dos casos a citologia associada a imunofenotipagem e porcentagem de células em fase S permitiram um diagnóstico correto. Nos demais casos foi possivel diferenciar linfomas $B$ ou $T$ e estimar grau de agressividade. O painel, embora pequeno, foi suficiente exceto para os anaplásicos e subclassificação dos linfomas T. Nestes casos, a morfologia foi mais importante que imunofenótipo, sendo este seguro apenas para linfomas linfoblásticos. A fração de fase $S$ mostrou-se importante para diferenciar linfomas indolentes e de alto grau. Concluimos que esta técnica é uma boa alternativa para o diagnóstico de linfomas não-Hodgkin. Permite um diagnóstico rápido, menos invasivo, podendo ser repetida quando necessário, agilizando o tratamento. Rev. bras. hematol. hemoter. 2005;27(1):16-20.
\end{abstract}

Palavras-chave: Aspiração por agulha fina; citometria; citologia; linfoma não-Hodgkin; imunofenotipagem.

\section{Introdução}

Com o intuito de agilizar a investigação de neoplasias tem-se usado cada vez mais a técnica de aspiração de tecidos por agulha fina. Esta permite definir conduta mais rápida quando comparado ao tempo necessário para o diagnóstico definitivo por histologia convencional.

Para tumores como melanoma, carcinomas de mama, metástases, entre outros, têm-se conseguido diagnósticos acurados, tornando esta técnica confiável e com utilidade bem definida. ${ }^{1}$
Em relação às doenças linfoproliferativas, muitos estudos estão sendo realizados no sentido de estabelecer sua confiabilidade no diagnóstico e conduta clínica. Tem-se proposto que a imunofenotipagem por citometria de fluxo aliada à citologia convencional poderia ser um método rápido e não invasivo para o diagnóstico dos linfomas. ${ }^{2,3}$ Além disso, a análise do ciclo celular ${ }^{4} \mathrm{e}$ a biologia molecular certamente poderiam aumentar a acurácia do diagnóstico fornecido através de punção de linfonodos. Recentemente foi descrita a classificação para neoplasias linfóides proposta pela OMS, que é baseada no conceito de que o diagnóstico deve ser

\footnotetext{
${ }^{l}$ Centro de Hematologia e Hemoterapia

${ }^{2}$ Departamento de Anatomia Patológica

Universidade Estadual de Campinas (Unicamp)

Correspondência para: Flávia Pinheiro S. Costa

Hemocentro Unicamp - Caixa Postal 6198

13081-970 - Campinas-SP

E-mail: fpinheirosc2002@yahoo.com.br
} 
baseado em morfologia, imunofenotipagem, alterações citogenéticas e clínicas. ${ }^{5}$

Tendo todas estas premissas em vista, tivemos como objetivo testar a factibilidade e acurácia do diagnóstico de linfomas não-Hodgkin combinando citologia, imunofenotipagem e estudo do ciclo celular (taxa de proliferação e ploidia) por citometria de fluxo, através de material obtido de linfonodos por punção com agulha fina. $\mathrm{O}$ diagnóstico final foi comparado com a biópsia convencional de linfonodo. Desta forma, o método proposto poderia estabelecer um diagnóstico seguro, rápido e não invasivo.

\section{Casuística e Métodos}

O estudo foi realizado com casos acompanhados no ambulatório de Hematologia - Hemocentro/Unicamp, entre 1999 e 2003 . Entraram no estudo pacientes que se apresentavam com linfonodomegalias ou massas tumorais acessíveis para punção por agulha fina, todos com hipótese inicial de linfoma ou suspeita de recaída. Os casos de linfoma de Hodgkin foram excluídos do estudo. Todos os pacientes tiveram amostras histológicas encaminhadas para o Serviço de Anatomia Patológica do Hospital de Clínicas - Unicamp, considerada como gold standard para o diagnóstico de linfoma.

Do material obtido por aspiração foram realizados:

- Esfregaços corados com May Grünewald Giensa

- Suspensão de células em PBS (no mínimo 6 X $10^{6}$ células) para análise em citometria de fluxo

$\mathrm{O}$ citômetro utilizado foi o FaCScalibur. A análise foi feita através do software CellQuest.

A citometria de fluxo foi usada para a análise do fenótipo da população neoplásica, a ploidia e medir a taxa de proliferação celular (porcentagem de células em fase $\mathrm{S}$ do ciclo celular). O painel de anticorpos monoclonais (DAKO A/S Denmark) foi o seguinte: CD19/CD10, CD20/CD5, CD38/CD7, CD23, CD3/CD4, CD3/CD8, kappa/lambda (membrana)

$\mathrm{O}$ aspirado de linfonodo colhido em $2 \mathrm{~mL}$ de PBS foi centrifugado por cinco minutos a 1500 RPM, e o sobrenadante ressuspendido em $1 \mathrm{~mL}$ de PBS. Após ajustar a concentração de células $\left(5 \times 10^{6} / \mathrm{mL}\right)$, o material foi incubado com $5 \mathrm{uL}$ de cada anticorpo por vinte minutos, à temperatura ambiente. Acrescentaram-se $2 \mathrm{~mL}$ de solução lisante (Facs lysing-BD) e, após dez minutos à temperatura ambiente, o material foi centrifugado por cinco minutos a 1500 RPM. Desprezado o sobrenadante, adicionaram-se $2 \mathrm{~mL}$ de PBS com nova centrifugação e ressuspensão em $1 \mathrm{~mL}$ de PBS. Aquisição e leitura no citômetro de 10 mil células foram feitas no software CellQuest.

Para o estudo do ciclo celular (DNA), após acertar a concentração de células em 1x 10\% $/ \mathrm{mL}$, colocaram-se $3 \mathrm{~mL}$ de solução lisante. Após incubação, centrifugação e ressuspensão em $1 \mathrm{~mL}$ de PBS, o material foi então fixado com $2 \mathrm{~mL}$ de álcool a $70 \%$, levado a refrigeracão por trinta minutos e centrifugado por cinco minutos a 1500 RPM. Desprezado o sobrenadante, acrescentamos $2 \mathrm{~mL}$ de PBS e centrifugamos por cinco minutos a $1500 \mathrm{RPM}(2 \mathrm{x})$.

O Kit utilizado foi Cycle Test-BD, que contém 3 soluções A (Tripsina), B (RNAse, inibidor da tripsina) e C (Iodeto de propídio). Cada uma destas foi adicionada à amostra que, após incubação, foi lida ao citômetro em até três horas. Aquisição de 30 mil células no software CellQuest e análise no software ModFit. Amostras obtidas por biópsia cirúrgica foram diagosticadas por hematopalogistas experientes após colorações com HE, Giemsa, Gomori e imuno-histoquímica. A classificação utilizada foi a proposta pela OMS.

\section{Resultados}

Entraram no estudo 78 casos. A idade mediana dos pacientes foi de 58 anos (17-85 anos). O diagnóstico final dos casos está na Tabela 1 . A maioria $(85 \%)$ correspondeu a linfomas de origem B e 15\% a origem T. Dos linfomas de origem $\mathrm{B}$, os mais freqüentes foram os LNH B de grandes células e folicular.

\begin{tabular}{lc}
\multicolumn{2}{c}{ Tabela 1 } \\
\multicolumn{1}{c}{ Diagnóstico histológico dos casos } \\
\hline \multicolumn{1}{c}{ Diagnósticos } & $N^{\circ}$ casos \\
\hline B grandes células & 40 \\
Folicular & 15 \\
Manto & 5 \\
Burkitt & 4 \\
Imunocitoma & 2 \\
T periférico & 5 \\
Linfoblástico & 4 \\
T do adulto & 2 \\
Anaplásico & 1
\end{tabular}

Os padrões imunofenotípicos, ploidia e proliferação estão relacionados nas Tabelas $2-5$. Entre os LNH B de grandes células tivemos cinco casos CD5+, apenas três casos CD38+ e nove casos CD10+. A maioria (29) foi positiva para imunoglobulina (Ig) de superfície.

Quanto à cinética celular, 26 casos foram euplóides e nove casos aneuplóides; a mediana de células em fase $\mathrm{S}$ do ciclo celular foi de 13,8\% (Tabelas 2 a e $2 b$ ).

Os LNH foliculares foram todos negativos para CD5 e CD23, mas nem todos os casos foram positivos para CD10 (9 casos). Apenas 4 casos foram aneuplóides, 11 euplóides. A mediana de fase $\mathrm{S}$ foi $3 \%$ (Tabelas $3 \mathrm{a}$ e $3 \mathrm{~b}$, Figura 1).

Os casos de linfoma de Burkitt mostraram fase $\mathrm{S}$ com mediana de $38 \%$, enquanto os linfomas de células do Manto (CD5+) 1,9\% (Tabela 4 e Figuras 2 e 3).

Os linfomas de origem $\mathrm{T}$ mostraram positividade em $100 \%$ dos casos para CD3 (Tabela 5). 


\begin{tabular}{|c|c|}
\hline \multicolumn{2}{|c|}{$\begin{array}{c}\text { Tabela } 2 \\
\text { Linfoma B células grandes }\end{array}$} \\
\hline \multicolumn{2}{|c|}{ Tabela $2 \mathrm{~A}$} \\
\hline Fenótipo & $\mathrm{N}^{\circ}$ casos \\
\hline CD19 & 35 \\
\hline CD 10 & 9 \\
\hline CD 38 & 3 \\
\hline CD 5 & 5 \\
\hline lg superf. & 29 \\
\hline \multicolumn{2}{|c|}{ Tabela 2 b } \\
\hline Cinética celular & $\mathrm{N}^{\circ}$ casos \\
\hline Aneuploidia & 9 \\
\hline Euploidia & 26 \\
\hline Fase S & $\begin{array}{c}\text { mediana } 13,8 \% \\
(10,6-43 \%)\end{array}$ \\
\hline
\end{tabular}

\begin{tabular}{|c|c|}
\hline \multicolumn{2}{|c|}{$\begin{array}{c}\text { Tabela } 3 \text { a } \\
\text { Linfomas foliculares }\end{array}$} \\
\hline Fenótipo & $\mathrm{N}^{\circ}$ casos \\
\hline CD19 & 15 \\
\hline CD 10 & 9 \\
\hline lg superf. & 7 \\
\hline \multicolumn{2}{|c|}{ Tabela $3 \mathrm{~b}$} \\
\hline Cinética celular & $\mathrm{N}^{\circ}$ casos \\
\hline Aneuploidia & 4 \\
\hline Euploidia & 11 \\
\hline Fase S & $\begin{array}{r}\text { mediana } 3 \% \\
(0,6-8,2 \%)\end{array}$ \\
\hline
\end{tabular}
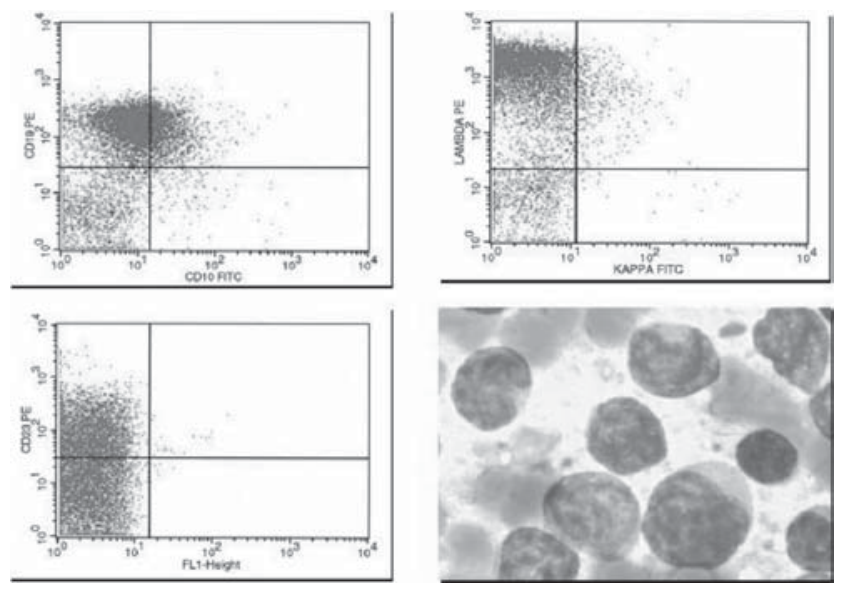

Figura 1. Linfoma folicular

\begin{tabular}{|c|c|c|c|}
\hline \multicolumn{4}{|c|}{$\begin{array}{c}\text { Tabela } 4 \\
\text { Outros linfomas B }\end{array}$} \\
\hline Histologia & Fenótipo & \multicolumn{2}{|c|}{ Cinética celular } \\
\hline & & Diploidia & $100 \%$ \\
\hline Burkitt & CD19/CD10 & $\%$ Fase S & $\begin{array}{c}\text { mediana } 38 \% \\
(31-44 \%)\end{array}$ \\
\hline \multirow{3}{*}{ Manto } & \multirow{3}{*}{ CD19/CD5 } & Aneuploidia & 2 casos \\
\hline & & Diploidia & 3 casos \\
\hline & & $\%$ Fase S & $\begin{array}{c}\text { mediana } 1,9 \% \\
(0,4-5,3 \%) \\
\end{array}$ \\
\hline \multirow{3}{*}{ Imunocitoma } & \multirow{3}{*}{$\begin{array}{c}\text { CD19/CD38 } \\
\text { lg }\end{array}$} & Aneuploidia & 1 caso \\
\hline & & Euploidia & 1 caso \\
\hline & & $\%$ Fase S & 0,6 e $1,5 \%$ \\
\hline
\end{tabular}
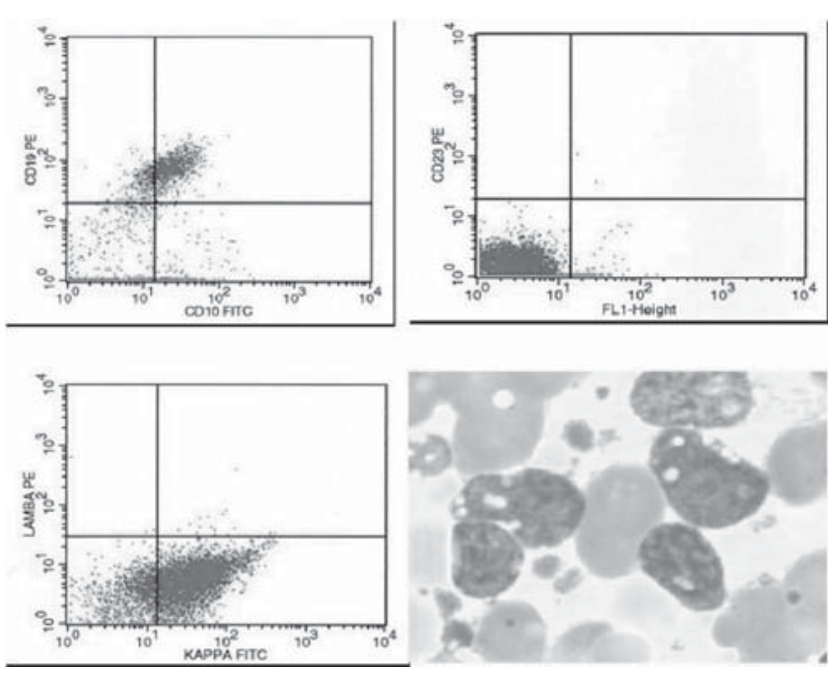

Figura 2. Linfoma de Burkitt
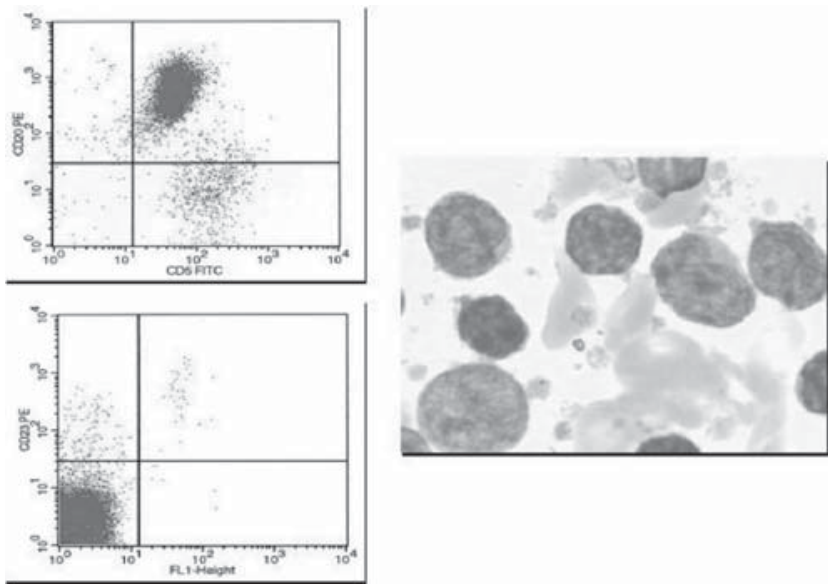

Figura 3. Linfoma de células de Manto 


\begin{tabular}{cccc}
\multicolumn{5}{c}{ Tabela 5 } \\
Linfomas T
\end{tabular}

\section{Discussão}

Frente a pacientes com linfocitose ao hemograma ou linfonodomegalia procuramos obter respostas para as seguintes questões:

- Trata-se de um processo reacional ou proliferação clonal de linfócitos?

- Se for clonal, a célula proliferante é B ou T?

- Podemos fazer o diagnóstico específico?

A precisão diagnóstica por morfologia, mesmo quando auxiliada por imuno-histoquímica para vários marcadores, é insuficiente em alguns casos de linfoma. ${ }^{6}$ Atualmente, novas modalidades diagnósticas estão sendo pesquisadas, mais recentemente o uso de microarranjos de DNA com o intuito de caracterizar padrões de expressão gênica. Essa assinatura gênica inclui genes que controlam o ciclo celular, síntese de DNA, replicação celular, além do Ki 67, comumente utilizado como índice de proliferação.

No caso dos LNH B de grandes células têm-se considerado dois subgrupos que se diferenciam pela expressão de centenas de genes. O primeiro expressa genes característicos de células $\mathrm{B}$ do centro germinativo ( $\mathrm{CD} 10, \mathrm{BCl}$ 6); o segundo grupo, genes característicos de células $\mathrm{B}$ ativados na periferia (IRF 4, Ciclina D2). A partir desta definição foram realizados estudos para tentar correlacionar os subgrupos com a clínica e sobrevida dos pacientes. De acordo com eles tem-se verificado que os LNH B de grandes células com expressão de linfócitos ativados na periferia mostram pior prognóstico. A expressão de $\mathrm{BCl} 2$, Ciclina D2, superexpressão de p53 e altas taxas de proliferação (\% células em fase $\mathrm{S}$ ) se correlacionam com pior prognóstico. A expressão gênica seria fator prognóstico independente. ${ }^{7,8}$ Esta técnica, porém, não faz parte da rotina de diagnóstico dos serviços de Onco-hematologia, permanecendo no campo da pesquisa.

Como técnica mais simples e acessível na rotina, a punção de tecidos por agulha fina tem-se mostrado uma boa opção no sentido de agilizar as respostas a essas perguntas. É rápida, pouco dolorosa, dispensa centro cirúrgico e internação. ${ }^{9}$ É capaz de prover com facilidade células em suspensão a serem analisadas por citometria de fluxo, além de material para esfregaços para citologia. As limita- ções seriam pacientes com lesões pouco acessíveis, profundas ou pequenas. Estas limitações estão sendo ultrapassadas em alguns serviços que contam com especialistas em diagnóstico por imagem que têm adquirido experiência na punção de tumores guiada por ultra-sonografia ou tomografia computadorizada. Por outro lado, o uso desta técnica exige a disponibilidade de um citômetro de fluxo e citopatologistas experientes para a análise correta das informações que fornece já que nem todos os casos são clássicos e muitas vezes representam verdadeiros desafios diagnósticos. ${ }^{10}$

A citometria de fluxo tem cada vez mais conquistado importância no diagnóstico e caracterização de neoplasias hematológicas. Tem como vantagens fornecer resultados rápidos utilizando pequenas amostras, além da capacidade de avaliar simultaneamente várias características celulares como tamanho, granularidade, antígenos de superfície e intracelulares, além do conteúdo celular de DNA. ${ }^{11,12,13}$ É extremamente útil para diferenciar, rapidamente, um processo reacional de outro neoplásico. Uma população de linfócitos B com restrição para uma cadeia leve de imunoglobulina (kappa ou lambda) é considerada neoplásica, com raríssimas exceções. Em linfonodos normais ou reacionais, os linfócitos B são policlonais, ou seja, expressam kappa e lambda na proporção de $60 \%$ para $40 \%$. A citometria de fluxo tem a habilidade, portanto, de detectar monoclonalidade com facilidade.

A determinação de imunofenótipos distintos permite classificar neoplasias linfóides de acordo com a célula de origem, já que tais neoplasias, principalmente as B, simulam estágios normais da diferenciação do linfócito. Esta subclassificação mais precisa leva não só ao diagnóstico, mas também a novas modalidades terapêuticas como, por exemplo, o uso de anti CD20 como terapia adjuvante em LNH CD $20+$.

Diagnosticar linfomas T por citometria de fluxo é mais desafiador, já que não há um marcador sensível de monoclonalidade. Situações como pós-transplante de medula óssea e infecções virais podem estar associadas com predomínio de linfócitos CD4 e CD8, respectivamente, assim como uma população clonal de células T.

Outra consideração deve ser feita em relação aos linfomas de Hodgkin, que foram desconsiderados neste estudo. Estes são linfomas com poucas células diagnósticas que prescindem de um antígeno específico, portanto, muitas vezes não detectáveis pela citometria de fluxo.

Através deste método conseguimos obter respostas para as três questões formuladas anteriormente, obtendo um diagnóstico em menos de 24 horas. O painel utilizado, embora pequeno, foi suficiente em todos os casos, exceto nos linfomas anaplásicos. 
Em relação aos LNH B grandes células houve casos com CD38 ou CD5 positivo, mas a $\%$ fase $\mathrm{S}$ permitiu distinção deste com linfomas indolentes. Percebe-se a importância da determinação da taxa de proliferação nestes casos em que a origem do tumor é similar, mas a agressividade é diferente. Outro exemplo tivemos com linfomas de Burkitt e foliculares. Ambos derivam de células dos centros foliculares e têm imunofenótipos comparáveis, mas diferem dramaticamente na porcentagem de células em fase S. Há estudos que mostram que a taxa de proliferação aparece como fator prognóstico independente para $\mathrm{LNH}^{3,11,14}$ A aneuploidia foi mais comum em casos de LNH B grandes células.

Em $85 \%$ dos casos, a citologia e citometria de fluxo permitiram um diagnóstico correto, ou seja, correlação com anatomopatológico. Nos casos restantes (15\%) foi possível apenas classificar o linfoma em B ou T e estimar a agressividade através da taxa de proliferação. Em cinco casos de linfoma T não foi possível subclassificá-los. Percebemos a importância da citologia nesses casos, sendo a morfologia das células neoplásicas mais importante que imunofenótipo para o diagnóstico. Nos linfomas B, citologia e imunofenótipo foram complementares para o diagnóstico.

O painel utilizado, apesar de ser pequeno, foi suficiente para os diagnósticos, exceto em casos de LNH T e anaplásicos. Portanto, concluímos que, combinando citologia e imunofenotipagem com material obtido através de aspirado de linfonodos, é possível agilizar o diagnóstico de maneira menos invasiva para o paciente possibilitando iniciar terapêutica mais rapidamente.

\section{Abstract}

The WHO classification of non-Hodgkin's lymphoma stresses the importance of the immunophenotype for diagnosis. The aim of our study was to evaluate the use of cytology together with flow cytometric examination using a panel of monoclonal antibodies including DNA Sphase analysis. Material was obtained from lymph node aspiration of 78 patients. The panel for flow cytometric analysis comprised: CD19/CD10, CD20/CD5, CD23, CD3/CD4, CD3/CD8, CD38/ CD7, kappa/lambda. The final diagnosis was confirmed by lymph node biopsy. In $85 \%$ of cases, cytology combined with immunophenotyping and percentage of Phase S cells allowed the correct diagnosis. In the remaining cases it was possible to differentiate $T$ or B lymphomas and estimate their aggressiveness. The panel, although small, was sufficient in all cases except for anaplastic lymphoma. S-phase fraction was important for the diagnosis of large B-cell NHL vs. Follicular NHL. In cases of T-cell lymphomas a reliable diagnosis was only possible for lymphoblastic lymphomas. In conclusions, combined cytology and cytophotometric diagnosis of lymph node aspirations is a good alternative to histologic examination, except for T-cell lymphomas. In contrast to biopsy this method is less invasive and may be repeated if necessary. Rev. bras. hematol. hemoter. 2005;27(1):16-20.

Key words: Fine needle aspiration cytology; flow cytometry; nonHodgkin's lymphoma; immunophenotyping.

\section{Referências Bibliográficas}

1. Orell S, Sterrett GF, Walters M N-I et al. Manual and atlas of fine needle aspiration cytology. Edinburgh, London, Madrid, New York and Tokyo: Churchill Livingstone 1992:64-93.

2. Robins DB, Katz RL, Swan F Jr et al. Immunotyping of lymphoma by needle aspiration. A comparative study of cytospin preparations and flow cytometry. Am J Clin Pathol 1994;101: 569-576.

3. Joenssuu H, Klemi PJ, Eerola E. Diagnostic value of DNA flow cytometry combined with fine needle aspiration biopsy in lymphomas. J Pathol 1998;154:237-345

4. Lehtinen T, Aine R, Lehtinen M et al. Flow cytometric DNA analysis of 199 histologically favourable or unfavourable non Hodgkin's lymphoma. J Pathol 1989;157:27-36.

5. WHO. Tumours of Haematopoietic and Lymphoid Tissues 2001,121-126.

6. Ben-Ezra J. B cell lymphoproliferative disorders. Hematol Oncol Clin N Am 2002;16:321-337.

7. Rosenwald A, Wright $\mathrm{G}$ et al, The use of molecular profiling to predict survival after chemotherapy for diffuse large B cell Lymphoma, N Engl J Med 2002;346:1937-1947.

8. Alizadeh AA, Eisen MB et al. Distinct types of diffuse large B cell lymphoma identified by gene expression profiling, Nature 2000; 403:503-511.

9. Siebert JD, Lori MLT et al. Utility of flow cytometry immunophenotyping for the diagnosis and classification of lymphoma in community hospital clinical needle aspiration/biopsies, Arch pathol Lab Med 2004;124:1792-1799.

10. Landgren O, MacDonald, OP et al. A prospective comparison of fine needle aspiration cytology and histopathology in the diagnosis and classification of lymphomas. The Hematol J 2004;5:69-76.

11. Stevenson MS, Braylan RC. Flow Cytometric analysis of lymphomas and lymphoproliferative disorders. Seminars in Hematol 2001;38:111-123.

12. Joenssuu H, Klemi PJ, Sodestrom S et al. Comparison of $\mathrm{S}$ phase fraction, Working Formulation and Kiel classification in non Hodgkin's lymphomas. Cancer 1991:1564-1571.

13. Gorczyca W, Tugulea S, Zach L. Flow cytometry in the diagnosis of mediastinal tumors with emphasis on differentiating thymocytes from precursor T lymphoblastic lymphoma/ leukemia. Leukemia \& Lymphoma 2004;45:529-538

14. Metze I, Costa F, Pereira F et al. Proliferation in non-Hodgkin's lymphomas and its prognostic value related to staging parameters. Cell Oncol 2004;26:63-71.

Avaliação: Editor e dois revisores externos.

Conflito de interesse: não declarado

Recebido: 14/09/04

Aceito após modificações: 15/02/05 